УДК 676.166:541.12

\title{
СВОЙСТВА ПЕРОКСИДНОЙ ЦЕЛЛЮЛОЗЫ ИЗ ОДНОЛЕТНИХ РАСТЕНИЙ. 5. ДЕФОРМАЦИОННЫЕ СВОЙСТВА ЛИСТА*
}

\author{
() Р.3. Пен ${ }^{1 * *}$, Я.В. Казаков ${ }^{2}$, Н.В. Каретникова ${ }^{1}$, И.А. Виивкова ${ }^{1}$ \\ ${ }^{1}$ Сибирский государственный технологический университет, пр. Мира, 82, \\ Красноярск, 660049 (Россия), e-mail:sibstu@sibstu.kts.ru \\ ${ }^{2}$ Северный (Арктический) фредеральный университет, наб. Северной Двины, \\ 17, Архангельск, 163002 (Россия)
}

\begin{abstract}
Пероксидная целлюлоза (получена делигнификацией реакционной смесью $« \mathrm{H}_{2} \mathrm{O}_{2}-\mathrm{H}_{2} \mathrm{O}-\mathrm{AcOH}-\mathrm{AcOOH}-$ катализатор») и сульфатная целлюлоза из стеблей пшеничной соломы размолоты до $28-30^{\circ}$ ШР. Определены деформационные свойства бумажных отливок: модуль упругости, работа деформации, жесткость и продолжительность релаксации при растяжении и др. При одинаковых механических напряжениях лист из соломенной целлюлозы деформируется в большей степени, чем из древесной, а из сульфатной целлюлозы - в большей степени, чем из пероксидной.

Ключевые слова: солома пшеницы, пероксидная делигнификация, целлюлоза из соломы, целлюлозные волокна.
\end{abstract}

\section{Введение}

Наибольшее значение при оценке потребительских свойств технической целлюлозы, бумаги и картона имеет испытание на растяжение. Получаемые при этом кривые зависимости «нагрузка-удлинение» $(F-\Delta l)$ и «напряжение-деформация» $(\sigma-\varepsilon)$ являются интегральной характеристикой деформационного поведения целлюлозно-бумажных материалов при растяжении.

Анализ зависимости «напряжение-деформация» при статическом нагружении образца бумаги позволяет выделить четыре области действия различных механизмов деформирования и разрушения (рис. 1) [2].

На начальном отрезке (между точками 0 и 1 на кривой) зависимость между напряжением $\sigma$ и деформацией $\varepsilon$ линейна. Это область упругого деформирования волокон и межволоконных связей. Точка 1 соответствует пределу упругости $\sigma_{1}$.

Отрезок между точками 1 и П криволинейный. Считается [2], что это обусловлено извлечением кон-

Пен Роберт Зусьевич - профессор кафедры целлюлозно-бумажного производства и химических волокон, доктор технических наук, тел.: (391) 227-37-10; e-mail: robertpen@yandex.ru Казаков Яков Владимирович - заведующий кафедрой технологии целлюлозно-бумажного производства, кандидат технических наук, доцент,

тел.: (8182) 65-74-82, e-mail: j.kazakov@ narfu.ru Каретникова Наталья Викторовна - доцент кафедры целлюлозно-бумажного производства и химических волокон, кандидат химических наук, тел.: (391) 227-37-10; e-mail: karetnikova.tata@yandex.ru Виивкова Ирина Анатольевна - аспирант кафедры целлюлозно-бумажного производства и химических волокон, тел.: (391) 227-37-10; e-mail: Sergeih_VSV@mail.ru цов неразорванных волокон, длина которых $l$ меньше критического значения $l_{\kappa p}$, из стенок трещин, образовавшихся в структуре листа. Развитие трещин сдерживается более длинными волокнами $l>l_{\kappa p}$, концы которых оказываются закрепленными по разным сторонам трещины (образования такого типа получили название «крейзы» [3]).

В области напряжений, которым соответствует отрезок кривой между точками П и В, происходит выдергивание концов волокон с разрушением межволоконных связей и преодолением сил трения. Сдвиговые касательные напряжения и «крейзование» вызывают пластическую деформацию.

\footnotetext{
*Предыдущее сообщение см. [1]

** Автор, с которым следует вести переписку
} 
Линейный отрезок между точками В и Р соответствует разрушению межволоконных связей у вершин трещин. Деформация в этой области завершается разрывом испытуемого образца.

\section{Экспериментальная часть}

Объектом исследования служили образцы пероксидной и сульфатной целлюлозы из пшеничной соломы и еловой древесины и отливки из них, условия изготовления и характеристики которых приведены в предыдущих сообщениях $[1,6]$.

Для определения характеристик деформативности отливок при растяжении использовали испытательный комплекс, включающий разрывную машину «Тестсистема 101», персональный компьютер и специальное программное обеспечение [2, 4]. При испытании образцов, нагружаемых с постоянной скоростью, регистрировались зависимости «нагрузка - удлинение». В ходе математической обработки по полученным экспериментальным кривым строились усредненные (по нескольким «параллельным» испытаниям) графики зависимости «напряжение - деформация» и определялись координаты характерных точек (рис. 1): предел упругости (1), эффективная точка (Э), начало пластической деформации (П), начало дополнительной вытяжки (В), разрушение образца (Р). Для каждой характерной точки рассчитывались величины прочностных и деформационных характеристик: напряжение $\sigma$, деформация $\varepsilon$, текущий модуль упру-

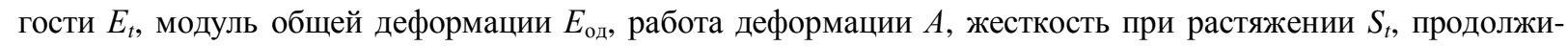
тельность релаксации напряжения $n[4,5]$.

\section{Обсуждение результатов}

На рисунке 2 приведены сглаженные и усредненные кривые зависимости «нагрузка - удлинение» для отливок из всех испытанных образцов целлюлозы, на рисунке 3 - зависимости «напряжение - деформация», характеризующие деформационное поведение материала. Различие проявляется в смене порядка кривых 1 и 4 в упругой и замедленно-упругой областях деформирования при переходе от координат «нагрузка - удлинение» к координатам «напряжение - деформация».

Вид растительного сырья существенно влияет на деформационные свойства целлюлозы. При одинаковых механических напряжениях оба образца из соломенной целлюлозы деформируются в большей степени, чем из древесной целлюлозы. Причиной этого, очевидно, является то, что структура отливки из соломенной целлюлозы сформирована из менее длинных, более тонких и более извитых волокон с большим числом изломов, с существенно меньшей грубостью $[1,6]$, они легче деформируются и снижают жесткость структуры.

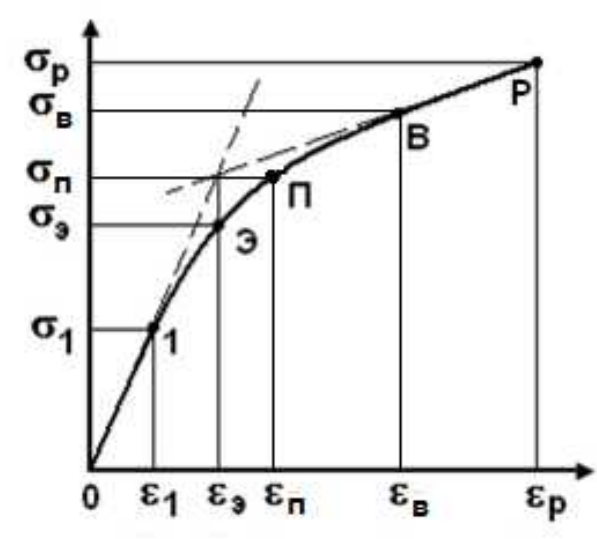

Рис. 1. Схема деформационных состояний бумажного листа при растяжении: $\varepsilon-$ деформация; $\sigma$ - напряжение. Характерные точки: 1 - предел упругости; Э - эффективная точка; П - начало пластической деформации; В начало дополнительной вытяжки; $\mathrm{P}$ - разрушение образца

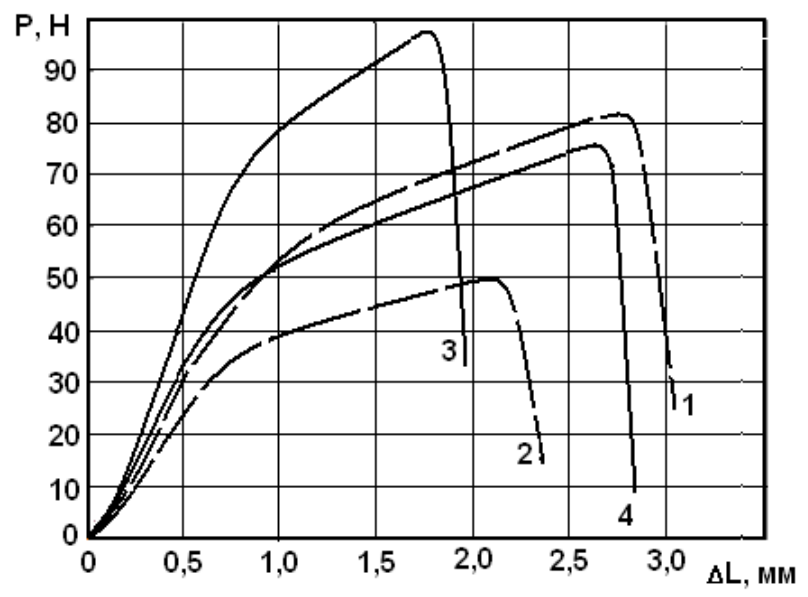

Рис. 2. Зависимости «нагрузка $(P)$ - удлинение $(\Delta L) »: 1-$ пероксидная целлюлоза из пшеничной соломы; 2 - сульфатная целлюлоза из соломы; 3 - пероксидная целлюлоза из еловой древесины; 4 - сульфатная целлюлоза из древесины 
Заметное влияние на обсуждаемые свойства оказывает и способ делигнификации. Кривые деформирования образцов из пероксидной целлюлозы (кривые 1 и 3 на рис. 3) располагаются выше, чем кривые для образцов из сульфатной целлюлозы (кривые 2 и 4 на рис. 3), т.е. отливки из сульфатной целлюлозы более подвержены деформациям, чем отливки из пероксидной целлюлозы. Волокна пероксидной целлюлозы об-

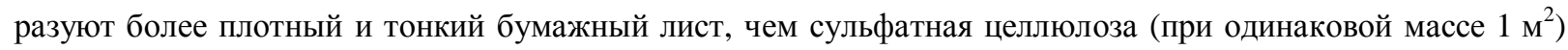
[1]. Упругие и жесткостные свойства бумажного листа в сильной степени определяются межволоконными силами связи. Для пероксидного способа варки характерны более селективная делигнификация и сохранение углеводного комплекса (гемицеллюлоз и низкомолекулярные фракции целлюлозы), который обеспечивает развитие поверхности волокон при размоле, повышение когезионной способности и способности к уплотнению во влажном состоянии.

На рисунках 4-7 представлены результаты более детального анализа изучаемых зависимостей.

В изменении характеристик жесткости структуры - текущего модуля упругости $E_{t}($ рис. 4 ) и модуля общей деформации $E_{\text {од }}$ (рис. 5) - просматриваются одинаковые закономерности: по мере увеличения деформации образца они снижаются, т.е. уменьшается жесткость структуры: наибольшие величины обоих модулей у отливок из пероксидной древесной целлюлозы (образец 3), наименьшие - у образцов из сульфатной соломенной целлюлозы (образец 4). Пониженная жесткость волокон соломенной целлюлозы может быть компенсирована переходом от сульфатного к пероксидному способу варки - величины характеристик примерно равны.

\section{б, МПа}

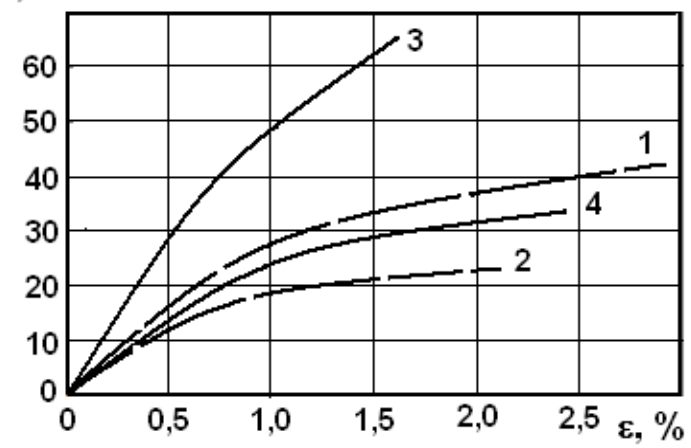

Рис. 3. Зависимости «напряжение $(\sigma)-$

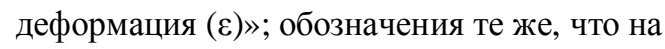
рисунке 2

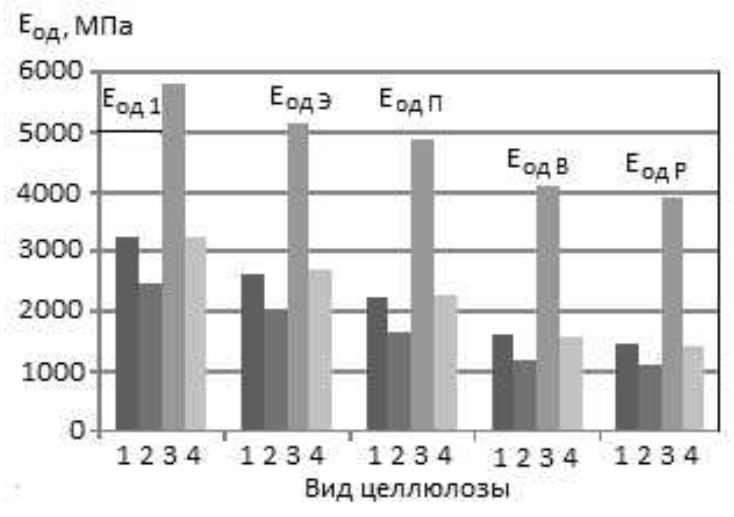

Рис. 5. Модуль общей деформации $E_{\text {од }}$ (обозначения вида целлюлозы и характерных точек те же, что на рисунке 4)

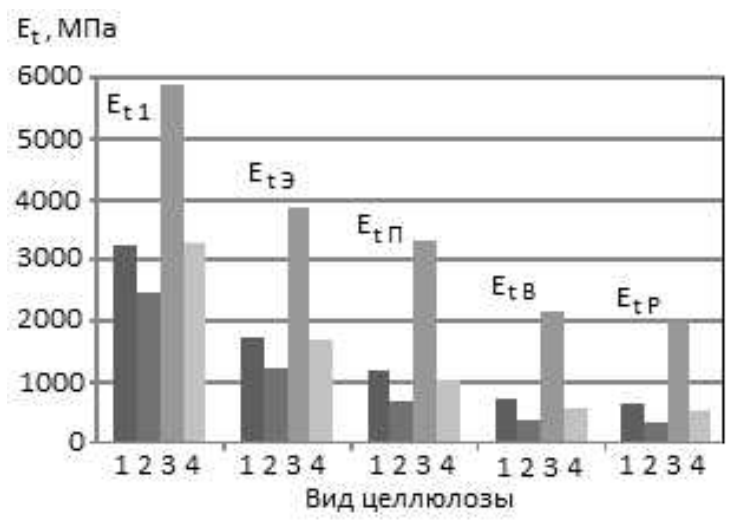

Рис. 4. Текущий модуль упругости $E_{t}$ (при растяжении) в точках 1, Э, П, В, Р (см. рис. 1). Вид целлюлозы: 1 - пероксидная из соломы; 2 - сульфатная из соломы; 3 - пероксидная из древесины; 4 - сульфатная из древесины

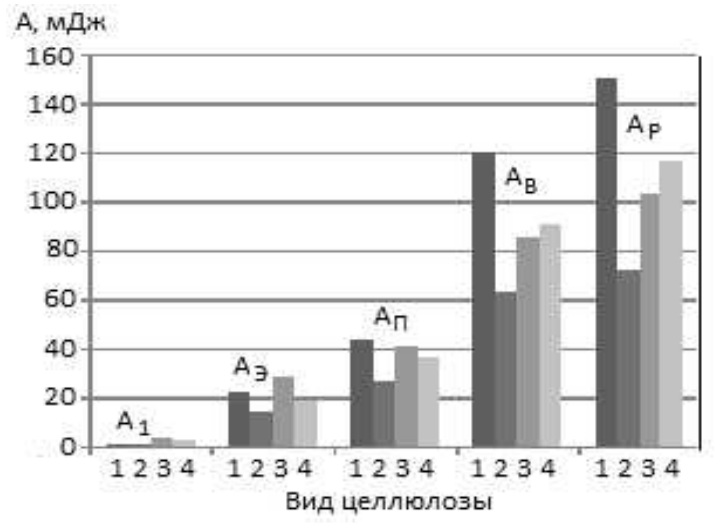

Рис. 6. Работа деформации $A$ (обозначения вида целлюлозы и характерных точек те же, что на рисунке 4) 


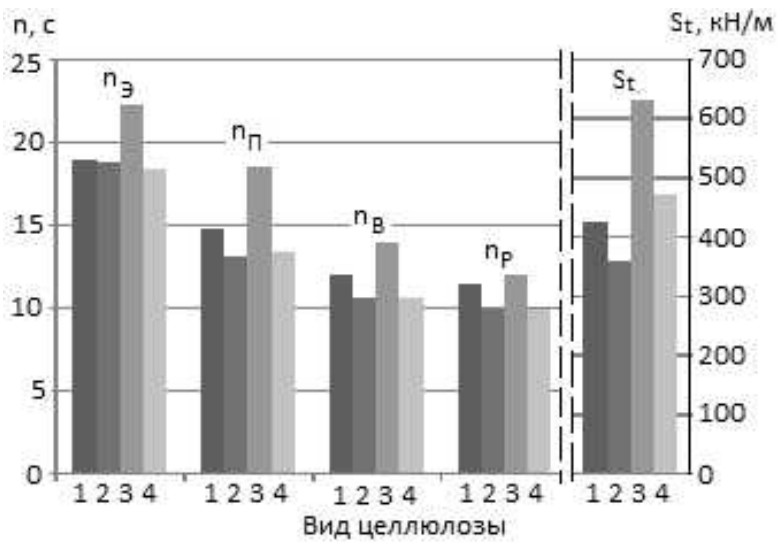

Рис. 7. Продолжительность релаксации $n$ и жесткость при растяжении $S_{t}$ (обозначения вида целлюлозы и характерных точек те же, что на рисунке 4)

Величина работы деформации $A$, являясь комплексной характеристикой прочности и растяжимости, характеризует динамическую прочность материала. Ранжирование образцов по этой характеристике меняется при переходе от зоны упругости к зоне предразрушения (рис. 6): при малых деформациях работа больше у отливок из древесной сульфатной целлюлозы, что связано с повышенной жесткостью волокон, а при больших деформациях - у отливок из соломенной пероксидной целлюлозы вследствие повышенной растяжимости структуры из тонких и гибких волокон.

Большое практическое значение имеют релаксационные свойства бумажного листа, так как в условиях эксплуатации материал часто претерпевает многократные деформации. Релаксационные процессы обусловливают гистерезисные явления, которые проявляются в несовпадении кривых «напряжение - деформация», полученных при постепенном увеличении и последующем уменьшении напряжения. После полной разгрузки испытуемый образец не возвращается к своей первоначальной длине, в нем сохраняется остаточная деформация. Наличие гистерезисной петли обычно связывают с пластической деформацией, однако это может быть и следствием релаксационного характера развивающейся деформации [2, с. 91]. Количественной характеристикой этого явления служит продолжительность релаксации напряжения $n$. Образцы целлюлозы ранжируются по этому показателю во всех характерных точках в том же порядке, что и жесткость при растяжении (рис. 7). Наибольшая продолжительность релаксации характерна для древесной пероксидной целлюлозы. Эта же целлюлоза заметно выделяется среди всех подвергнутых испытанию образцов высокими значениями текущих модулей упругости (рис. 4) и модулей общей деформации (рис. 5).

\section{Заключение}

Структура отливки из соломенной целлюлозы формируется из менее длинных, более тонких и более извитых волокон с большим числом изломов, с существенно меньшей грубостью в сравнении с сульфатной целлюлозой. Вследствие этого бумажный лист из соломенной целлюлозы легче деформируется, снижается жесткость его структуры.

Пониженная жесткость волокон соломенной целлюлозы может быть компенсирована переходом от сульфатного к пероксидному способу варки, для которого характерна более селективная делигнификация и сохранение углеводного комплекса, обеспечивающего развитие поверхности волокон при размоле, повышение когезионной способности и способности волокнистой структуры противостоять деформациям.

\section{Список литературы}

1. Пен Р.З., Казаков Я.В,, Каретникова Н.В., Вшивкова И.А. Свойства пероксидной целлюлозы из однолетних растений. 4. Размол волокнистой массы и прочность листа // Химия растительного сырья. 2013. №3. С. 59-63.

2. Комаров В.И. Деформация и разрушение волокнистых целлюлозно-бумажных материалов. Архангельск, 2002. $440 \mathrm{c}$.

3. Бартенев Г.М. Прочность и механизм разрушения полимеров. М., 1984. 280 с.

4. Комаров В.И., Казаков Я.В. Анализ механического поведения целлюлозно-бумажных материалов при приложении растягивающей нагрузки // Лесной вестник. 2000. № 3. С. 52-62.

5. Казаков Я.В. Практика использования характеристик деформативности для оценки качества бумаги и картона // Проблемы механики целлюлозно-бумажных материалов. Архангельск, 2011. С. 88-94.

6. Вшивкова И.А., Пен Р.З., Каретникова Н.В. Свойства пероксидной целлюлозы из однолетних растений. 3. Размерые характеристики волокон из пшеничной соломы // Химия растительного сырья. 2013. №2. С. 37-41. 
Pen R.Z..$^{*}$, Kazakov Y.V. ${ }^{2}$, Karetnikova N.V. ${ }^{l}$, Vshivkova I.A. ${ }^{l}$ PEROXIDE PULPING PROPERTIES OF ANNUAL PLANTS. 5. DEFORMATION PROPERTIES OF PULP SHEET

${ }^{1}$ Siberian State Technological University, Mira st., 82, Krasnoyarsk, 660049 (Russia), e-mail: sibstu@sibstu.ru

${ }^{2}$ Northern (Arctic) Federal University named after M.V. Lomonosov, Severnaya Dvina Emb. 17, Arkhangelsk, 163002 (Russia)

Peroxide pulp (received by means delignification with reactive mixture $\left\langle\mathrm{H}_{2} \mathrm{O}_{2}-\mathrm{H}_{2} \mathrm{O}-\mathrm{AcOH}-\mathrm{AcOOH}-\mathrm{catalyst}\right.$ ) and sulfate pulp from stems of wheat straw are beaten to $28-30^{\circ}$ SR. Deformation properties of pulp sheet are defined: modulus of elasticity, work of deformation, tension stiffness, relaxation time and others. of Straw pulp sheet is deformed more than wood pulp sheet and from sulphate pulp - under identical mechanical stress.

Keywords: wheat straw, peroxide delignification, pulp of wheat straw

\section{References}

1. Pen R.Z., Kazakov Ia.V,, Karetnikova N.V., Vshivkova I.A. Khimiia rastitel'nogo syría, 2013, no. 3, pp. $59-63$. (in Russ.).

2. Komarov V.I. Deformatsiia i razrushenie voloknistykh tselliulozno-bumazhnykh materialov. [Deformation and fracture of fibrous pulp and paper materials]. Arkhangelsk, 2002, 440 p. (in Russ.).

3. Bartenev G.M. Prochnost' $i$ mekhanizm razrusheniia polimerov. [Strength and fracture mechanism of polymers]. Moscow, 1984, 280 p. (in Russ.).

4. Komarov V.I., Kazakov Ia.V. Lesnoi vestnik, 2000, no. 3, pp. 52-62. (in Russ.).

5. Kazakov Ia.V. Problemy mekhaniki tselliulozno-bumazhnykh materialov. [Problems of pulp and paper materials]. Arkhangelsk, 2011, pp. 88-94. (in Russ.).

6. Vshivkova I.A., Pen R.Z., Karetnikova N.V. Khimiia rastitel'nogo syr'ia, 2013, no. 2, pp. 37-41. (in Russ.).

Received January 26, 2013

Revised February 3, 2013

\footnotetext{
* Corresponding author.
} 
